\title{
O design de interiores como prótese de gênero: um estudo sobre ambientes projetados para casais e para crianças
}

\section{Interior design as gender prothesis: a study about rooms designed for couples and for children}

\author{
Cláudia Regina Hasegawa Zacar, Universidade Federal do Paraná.
}

claudiazacar@ufpr.br

\author{
Marinês Ribeiro dos Santos, Universidade Tecnológica Federal do Paraná. \\ ribeiro@utfpr.edu.br
}

\section{Resumo}

Neste artigo tomamos como objeto de estudo a CASACOR Paraná ${ }^{\circledR}$, mostra de design, arquitetura e paisagismo que ocorre anualmente em Curitiba desde 1994. Analisamos fotografias e textos de apresentação de seis ambientes, expostos entre 1994 e 2018, projetados para o uso compartilhado por casais e por crianças. Procuramos reforçar que o design constitui, em sua prática, scripts de gênero que implicam em prescrições e proscrições que direcionam os usos dos sistemas projetados. Argumentamos ainda que as materialidades resultantes dos processos de design atuam como próteses que produzem sujeitos marcados pelo gênero. A partir desasas premissas, nossas análises evidenciam que as estratégias de individualização e diferenciação aplicadas a ambientes expostos na mostra são consonantes com uma perspectiva normativa das relações de gênero, articulada a modelos de casa e de família que remontam a ideais burgueses novecentistas.

Palavras-chave: História do Design, Teoria do Design, Design de interiores, Relações de Gênero.

\begin{abstract}
In this paper we take as object of study CASACOR Paraná ${ }^{\circledR}$, a design, architecture and landscaping show that has taken place annually in Curitiba since 1994. We analyzed photographs and texts related to six rooms, exhibited between 1994 and 2018, designed for the shared use by couples and by children. We seek to reinforce that the design practice constitutes gender scripts that imply prescriptions and proscriptions that guide the uses of the designed systems. We also argue that the materialities resulting from the design processes act as prosthesis that produce gendered subjects. Based on these premises, our analysis demonstrates that the individualization and differentiation strategies applied to the rooms that are exhibited in the show are in line with a normative perspective of gender relations, which is linked to models of home and family that date back to nineteenth-century bourgeois ideals.
\end{abstract}

Keywords: Design History, Design Theory, Interior Design, Gender Relations. 


\section{Introdução}

Atualmente, no Brasil, projetos de design de interiores têm ganhado destaque em uma série de revistas, programas de televisão e websites relacionados ao tema (ROSSETTI, 2014). Uma marca que se destaca nesse contexto é a $C A S A C O R^{\circledR 1}$, divulgada como "a maior e mais completa mostra de arquitetura, design de interiores e paisagismo das Américas" (GRUPO ABRIL, 2017). Inaugurada em 1987, na cidade de São Paulo, atualmente a $C_{A S A C O R^{\circledR}}$ se faz presente em 17 localidades no Brasil e 4 cidades no exterior (CASACOR, 2019).

A edição paranaense da mostra teve início na cidade de Curitiba em 1994. A CASACOR Paraná $^{\circledast}$ (CCPR) tem recebido uma média anual de público de cerca de 30 mil pessoas (MOTA, 2012) e exibiu, em suas 26 edições, mais de mil ambientes, desenvolvidos por cerca de 700 expositores/as. As/os visitantes da mostra no estado apresentam perfil similar ao estabelecido nas edições paulistanas, onde predomina a presença de "senhoras da sociedade" (PUGLIESI, 2014, p.42) - a saber: mulheres (75\%), com idade entre 20 a 39 anos (56\%) e pertencentes às classes A $(59 \%)$ e B (38\%) (GRUPO ABRIL, 2017).

Além do considerável número de visitantes, os eventos da CCPR têm sido divulgados em diferentes mídias, tais como jornais e programas de televisão locais, bem como por periódicos especializados. A organização da mostra edita regularmente um anuário impresso e também veicula fotografias dos ambientes expostos por meio de seu website e de seus perfis em redes sociais ${ }^{2}$.

A CCPR dá centralidade aos espaços idealizados como domésticos, apresentando-se como uma vitrine de tendências relacionadas ao morar (NESSI, 2013). Em geral, é organizada de forma a replicar a organização de uma moradia, com ambientes direcionados a usos e usuários/as específicos/as, que são decorados por diferentes profissionais locais.

Neste artigo, procuramos discutir como o design de interiores em exibição na mostra constitui noções sobre as relações de gênero no Brasil recente. Para tanto, analisamos imagens e textos referentes a seis ambientes expostos na CCPR entre 1994 e 2018. Selecionamos ambientes idealizados para o uso compartilhado por parte de casais e também por irmãos e irmãs, recorte que nos permite observar como padrões decorativos historicamente tidos como femininos e como masculinos são aplicados na decoração de um mesmo cômodo, de forma a explicitar seus contrastes e/ou estabelecer convergências.

Entendemos que esses padrões de configuração não são simplesmente meios de expressão de uma ordem "natural" pré-estabelecida, mas maneiras de (re)produzir normas de gênero culturalmente constituídas (PRECIADO, 2010). Nesse sentido, assumimos que o design de interiores torna tangíveis ideias e significados, atuando na construção e reiteração de

\footnotetext{
${ }^{1}$ A marca $C A S A C O R^{\circledR}$ é de propriedade exclusiva da Abril. As autoras mencionam a marca para fins de estudo e crítica, e se responsabilizam pelos dados aqui apresentados. Todos os créditos relativos aos projetos e textos de apresentação dos ambientes foram incluídos, e todo o conteúdo apresentado é proveniente de materiais de ampla divulgação.

${ }^{2}$ Disponíveis em: <https://casacor.abril.com.br/mostras/parana/>, <https://ptbr.facebook.com/casacorpr/>, <https://www.instagram.com/casacorpr/>.
} 
características ligadas a marcadores sociais, tais como o gênero. Dessa forma, atua também na constituição de subjetividades (SPARKE, 2004).

\section{Procedimentos metodológicos}

Este trabalho é fruto de uma pesquisa mais abrangente (ZACAR, 2018), para a qual foi feito um levantamento de todos os mais de mil ambientes expostos na CCPR entre 1994 e 2018. Foram pré-selecionados aqueles que tinham, em seu nome ou texto de apresentação, explícito direcionamento para um perfil específico de usuário(s)/a(s) (como por exemplo, "Suíte do Casal", "Suíte da moça" ou "Quarto do menino"). Esse primeiro recorte resultou em uma amostra de cerca de 200 ambientes, cujas imagens e descrições textuais (coletadas de publicações impressas ligadas à organização da CCPR, do website da mostra e de edições especiais da revista Casa Claudia) passaram por uma análise preliminar. A partir disso foram identificados temas chave, sendo um deles o uso compartilhado de ambientes - notadamente dormitórios e banheiros - por casais ou por irmãos/irmãs. Optamos por focar em dormitórios, por ser esse o tipo de cômodo mais recorrente dentro do tema estipulado. Selecionamos os ambientes a analisar tendo em vista seu ano de exibição, visando conferir certa distribuição temporal, e sua representatividade em termos de adequação ou tensionamento em relação aos padrões observados no conjunto de ambientes enquadrados no tema.

As imagens dos ambientes selecionados foram analisadas de forma mais aprofundada com apoio de um roteiro (Quadro 1), estruturado a partir do confronto com o material empírico e de aportes teórico-metodológicos relacionados aos Estudos sobre a Imagem. Foram utilizados como referência trabalhos da pesquisadora Gillian Rose (2007), da historiadora Ana Maria Mauad (2005) e de Laurent Gervereau (2004), autor ligado à História Visual. Tomamos também como base categorias utilizadas por Vânia Carneiro de Carvalho (2008) e Marinês Ribeiro dos Santos (2015), que tratam dos interiores domésticos no Brasil a partir da perspectiva dos estudos de gênero.

O roteiro foi organizado em duas partes, denominadas "Descrever" e "Relacionar". A primeira é voltada para a descrição detalhada dos elementos presentes na imagem, abrangendo tanto as características gerais da imagem quanto o seu conteúdo. A segunda destina-se a facilitar a construção de significados possíveis para a imagem, mediante o estabelecimento de relações de intertextualidade. 


\begin{tabular}{|c|c|}
\hline \multicolumn{2}{|c|}{ ROTEIRO PARA ANÁLISE DE IMAGENS } \\
\hline \multicolumn{2}{|c|}{ Etapa 1 - Descrever } \\
\hline Características Gerais da Imagem & Conteúdo da Imagem \\
\hline $\begin{array}{l}\text { Enquadramento } \\
\text { Sentido, objeto central, arranjo, equilíbrio, etc. }\end{array}$ & $\begin{array}{l}\text { Espaço } \\
\text { Dimensão aparente, segmentação, distâncias, etc. }\end{array}$ \\
\hline $\begin{array}{l}\text { Nível do olhar } \\
\text { Linha do horizonte, abaixo, acima }\end{array}$ & $\begin{array}{l}\text { Artefatos } \\
\text { Tipos, funções, mobilidade, etc. }\end{array}$ \\
\hline $\begin{array}{l}\text { Iluminação } \\
\text { Intensidade, fonte de luz dominante, sombras, efeitos, etc. }\end{array}$ & $\begin{array}{l}\text { Cores } \\
\text { Composição, predominância, efeitos, etc. }\end{array}$ \\
\hline & $\begin{array}{l}\text { Formas e volumes } \\
\text { Composição, predominância, efeitos, etc. }\end{array}$ \\
\hline & $\begin{array}{l}\text { Matérias-primas } \\
\text { Características e propriedades gerais, tipo de acabamento, } \\
\text { etc. }\end{array}$ \\
\hline & $\begin{array}{l}\text { Posturas, movimentos e práticas sugeridos, } \\
\text { possibilitados ou inibidos } \\
\text { Espaço disponível, arranjo de artefatos no espaço, grau de } \\
\text { instrumentalidade dos objetos, relações com o corpo, } \\
\text { scripts /programas de ação, etc. }\end{array}$ \\
\hline \multicolumn{2}{|c|}{ Etapa 2 - Relacionar } \\
\hline \multicolumn{2}{|c|}{$\begin{array}{c}\text { Conteúdo da imagem x Texto escrito } \\
\text { Contraponto/complemento }\end{array}$} \\
\hline \multicolumn{2}{|c|}{$\begin{array}{l}\text { Conteúdo da imagem x Conteúdo da série } \\
\text { Sincrônica / Diacrônica }\end{array}$} \\
\hline \multicolumn{2}{|c|}{$\begin{array}{l}\text { Conteúdo da imagem x Contexto } \\
\text { Dados demográficos, cenário econômico, referências culturais, símbolos e convençôes, estilos decorativos, valores da } \\
\text { CASACOR }{ }^{\circledR} \text { Paraná, perfil do público, etc. }\end{array}$} \\
\hline \multicolumn{2}{|c|}{ Conteúdo da imagem x Outros estudos } \\
\hline
\end{tabular}

Quadro 1: Roteiro para análise de imagens Fonte: ZACAR, 2018

\section{O design de interiores como prótese de gênero}

Seguindo Judith Butler (2014), entendemos que gênero diz respeito a um conjunto de normas socialmente estabelecidas que, ao serem constantemente citadas e reiteradas nas mais diversas instâncias - tais como os discursos científico e religioso, a escola, a família - são inscritas no corpo. Esse processo de incorporação das normas por meio de sua continua repetição é o que a filósofa chama de performatividade de gênero.

Consideramos que esses discursos, bem como práticas sociais e materialidades, produzem tipos de subjetividade com os quais os indivíduos podem se identificar, internalizar e viver como verdade (WEEDON, 2004). Porém, as normas de gênero limitam as possibilidades de identificação mediante a sexualização dos corpos e a naturalização de diferenças, a partir de uma lógica dicotômica (mulher/homem, masculino/feminino). 
(Paul) Beatriz Preciado ${ }^{3}$ toma a perspectiva de Butler como base para discutir como a tecnologia tem importância fundamental para a construção de corpos marcados pelo gênero. $O$ filósofo desenvolve a categoria de "prótese de gênero" para enfatizar que as fronteiras entre o "natural" e o "artificial" não são tão claras e intransponíveis como comumente se julga. O autor não limita essa ideia a artefatos de reabilitação, entendendo que diversas tecnologias que utilizamos cotidianamente atuam também como próteses - o telefone como prótese do ouvido, a televisão como prótese do olho e do ouvido, o cinema como prótese do sonho, etc. (PRECIADO, 2014).

Para Preciado (2014) o corpo, ao se conectar com esses diferentes órgãos protéticos, altera a estrutura de sua sensibilidade. Isso porque as próteses tecnicamente produzidas operam como filtros a partir dos quais são construídas nossas percepções, crenças e identidades, nossos afetos, desejos e comportamentos. Segundo o autor, a arquitetura e o design produzem materialidades que operam como próteses de gênero, considerando que elas podem possibilitar ou impedir diferentes tipos de percepção e comportamento - "criando marcos de visibilidade, permitindo ou negando acesso, distribuindo espaços, criando segmentações entre público e privado..." (PRECIADO, 2010, p. 128, tradução nossa).

Preciado (2014) chama a atenção para o fato de que as próteses de gênero são naturalizadas a partir de uma perspectiva binária, que estabelece padrões de feminilidade e de masculinidade constituídos como polos opostos, complementares e assimétricos. Historicamente esses padrões têm sido (re)produzidos na constituição dos interiores domésticos, a partir do estabelecimento de relações entre certos artefatos, cores, formas, motivos e configurações com ideias e valores vinculados a homens e a mulheres. Ambientes "femininos" foram associados ao uso de linhas curvas, cores claras, texturas brilhantes e lisas; enquanto ambientes "masculinos" foram ligados à aplicação de linhas retas, cores escuras e texturas rugosas (MANCUSO, 2002; GURGEL, 2013). Essas características se sobrepõem a concepções estereotipadas sobre o corpo, sendo o feminino entendido como cíclico, curvilíneo, frágil, passivo, delicado e macio; e o masculino tido como rígido, robusto, forte, ativo e áspero (SANT’ANNA, 2014).

Para pensar sobre como esses padrões são (re)produzidos na prática do design, recorremos ao trabalho de Ellen van Oost (2003), que desenvolve o conceito de "script (roteiro) de gênero". A autora utiliza esse conceito para tratar da forma como pressupostos que designers têm sobre as relações de gênero direcionam o processo projetual. Ela considera que designers e fabricantes inscrevem nos artefatos prescrições e proscrições (mais ou menos coercitivas) a partir de significados associados às feminilidades e às masculinidades. Segundo a autora, esses elementos inscritos nos sistemas projetados participam da construção das identidades das pessoas que deles se apropriam.

\footnotetext{
${ }^{3}$ O filósofo assinou parte de sua obra como Beatriz Preciado, conforme consta nas referências. Incluímos o nome Paul para respeitar a maneira como o autor tem mais recentemente se identificado.
} 


\section{A casa, a família e as relações de gênero na CASACOR Paraná $^{\circledR}$}

Na CCPR, os nomes dados aos ambientes, como "Suíte do Bebê", "Quarto do Casal" e "Banheiro dos filhos" - revelam seu caráter especializado e individualizado. Essas características remetem ao ideal de casa burguesa moderna, estabelecido na virada do século XIX para o XX.

Segundo Vânia Carneiro de Carvalho (2008), naquele período os ambientes privados passaram a ser idealizados como refúgio da família em relação às dificuldades da vida pública moderna, assumindo configurações voltadas a torná-los agradáveis e confortáveis. Ao mesmo tempo, as relações familiares foram se transformando, tornando-se mais pautadas na proximidade afetiva e na valorização da individualidade. Com isso, a casa burguesa foi se organizando de forma a estimular a intimidade e a privacidade como elementos chave para a constituição da identidade dos membros da família. Os interiores domésticos modernos passaram então a prever a individualização de cômodos, configurados de acordo, por exemplo, com o gênero e a idade de seus habitantes.

Os nomes dados aos ambientes expostos na CCPR também reforçam o direcionamento dado, em geral, a um modelo de família nuclear, constituída por casal heterossexual monogâmico e filhas/os. A mostra adere, assim, ao modelo de família que permanece, no imaginário de muitos setores da sociedade brasileira, como sendo o ideal, o desejável, ou mesmo o "natural" (MANDELBAUM, 2009).

Como indício desse fato, citamos que não foi possível identificar nenhum ambiente explicitamente projetado visando outros tipos de conjugalidade ou casais idealizados como gays ou lésbicos, no âmbito da mostra paranaense. Considerando outras mostras da CASACOR ${ }^{\circledR}$, encontramos poucos exemplos, como o "Quarto do Casal Gay", criado por Renata Dutra para a CASACOR Brasília ${ }^{\circledR}$ de 2011; e o "Loft dos Colecionadores", apresentado por Oscar Mikail na CASACOR São Paulo ${ }^{\circledR}$ de $2014^{4}$. Nos dois casos, foi explicitamente declarado se tratar de espaços específicos para usuários imaginados como homens homossexuais.

Os ambientes para casais apresentados na CCPR, via de regra, não recebem designação tão específica. Isso porque se adequam aos padrões heteronormativos - o "casal" é assumido como sendo heterossexual, pois é essa a convenção social atrelada ao matrimônio.

Esses ideais de conjugalidade e família são constituídos, na mostra, em articulação com noções acerca das relações de gênero, que são evidenciadas em ambientes direcionados ao uso compartilhado por casais (assumidos como heterossexuais) e também em cômodos idealizados para o uso conjunto entre irmãos e irmãs.

\footnotetext{
${ }^{4}$ Para uma análise desses ambientes, ver Zacar e Santos (2017).
} 


\section{Ambientes de uso compartilhado projetados para casais}

O "Quarto de dormir do casal", apresentado por Marilena Santos e Regina Castro em 1994, apresenta um arranjo simétrico parar as mesas de cabeceira e os espelhos presos à parede acima dessas, o que confere a sensação de constância e estabilidade. O quarto é mobiliado com uma cama de casal, ladeada pelas já mencionadas mesas de cabeceira, e um conjunto de penteadeira e cadeira. Todos os móveis são de madeira maciça escura, que remete a significados associados à permanência e à tradição, materializando um ideal de casamento sólido e duradouro.

Para a análise desse ambiente, tornam-se úteis as noções de "relações centrípetas" e "relações centrífugas", conforme apresentadas por Carvalho (2008) em seu estudo sobre as articulações entre corpo e objeto nos interiores domésticos paulistas da virada do século XIX para o XX. Segundo a autora, as interações entre o corpo e os artefatos que o circundam direcionam ações, sentidos e valores associados às normas de gênero.

Para Carvalho (2008), a relação corpo-objeto se dá, no contexto por ela analisado, de forma oposta para homens e para mulheres. No caso masculino, essa relação é regulada por um princípio de autorreferência, caracterizado por ações centrípetas, ou seja, marcadas pela apropriação de artefatos para fortalecer um perfil individualizado. Sendo assim, as coisas convergem para a figura masculina, e os artefatos associados a ela - tais como livros, acessórios, objetos de escritório, etc. - apresentam um cunho estritamente pessoal.

Já para as mulheres, a relação corpo-objeto se dá por meio de ações centrífugas, caracterizadas por uma apropriação inespecífica e extensiva do espaço doméstico. Com isso, configura-se um perfil pessoal predisposto a abrir mão da própria individualidade em prol da produção de uma identidade familiar, atuando como integrador das diferenças existentes entre os membros da família (CARVALHO, 2008).

Cabe ressaltar que a forte presença feminina na configuração dos interiores domésticos novecentistas se deve, em grande medida, à crença de que o lar era uma esfera predominantemente feminina. Segundo Carvalho (2008), essa presença era marcada por um repertório específico de artefatos, que com frequência tinham formas, cores e acabamentos inspirados na natureza. Flores, pássaros e ramagens eram motivos ornamentais recorrentes, assim como o uso de matérias-primas delicadas como seda, renda e pluma. Ainda de acordo com a autora, esses elementos associados ao "ser feminino" eram predominantes na sala de visitas, nos quartos femininos e nos quartos de casal.

No "Quarto de dormir do casal" são reproduzidos padrões similares, no contexto do fim do século XX. Na configuração do dormitório predominam características historicamente associadas à decoração tida como feminina, notadamente o uso de elementos que remetem à natureza. Dentre esses, se destaca um painel estampado com imagens de pássaros e ramagens, localizado atrás da cama.

Os objetos dispostos nas mesas de cabeceira revelam marcações de gênero - de um lado, um relógio e um livro; de outro, um vaso com flores e um porta-retratos. Os primeiros, historicamente associados às supostas racionalidade e praticidade masculinas; os segundos, vinculados à

\footnotetext{
${ }^{5}$ Imagem disponível em Nessi (2013).
} 
delicadeza e ao vínculo familiar tidos como "naturais" às mulheres. Nota-se, com isso, que apesar de ser um ambiente em que predominam elementos tidos como femininos, a presença masculina é sugerida por objetos ligados à individualização, em consonância com as observações de Carvalho (2008).

A predominância de elementos convencionados como femininos também se faz notar no "Quarto do casal", exposto em 2006 por Renata Pisani. Em relação a ele, é destacado o uso de um "estilo provençal com toque romântico" (NESSI, 2013), marcado pela aplicação de tons pastel e motivos florais.

Nesse ambiente é sugerida uma complementaridade entre cônjuges, por meio da combinação de artefatos convencionalmente associados aos homens e às mulheres. Em uma das paredes, encontra-se um conjunto de bancada e painel para televisão, confeccionado com madeira de cor escura e linhas retas - aspectos comumente associados a artefatos masculinos. Anexa à bancada, há ainda uma mini adega que remete ao consumo de bebidas alcóolicas, prática historicamente mais associada aos homens (CARVALHO, 2008). A parede oposta é revestida com um papel de parede branco e rosa, e conta com um adorno de motivos florais. O dormitório é também decorado com alguns arranjos de flores, e com um par de cadeiras revestidas com um tecido de estampa floral. Esses elementos retomam a associação entre um ideal de feminilidade e a natureza ${ }^{7}$.

O texto de apresentação desse ambiente destaca que os sistemas de automação nele utilizados possibilitam "o controle de cortinas, equipamentos de áudio e vídeo", bem como a movimentação de um quadro que recobre o aparelho de televisão, ocultando-o (NESSI, 2013, p. 83). Essa estratégia de esconder a televisão lembra artifícios analisados por Carvalho (2008) e Van Oost (2003), que identificam a prática de "camuflagem" de elementos técnicos como estratégia utilizada em ambientes e produtos associados às mulheres.

No caso de Van Oost (2003), que analisa o design de aparelhos elétricos de depilação produzidos pela multinacional Phillips no século XX, a prática de esconder as características técnicas dos produtos voltados ao público feminino é vista como uma maneira de inibir o interesse das mulheres pela tecnologia reforçando, com isso, a ideia de que elas são tecnicamente incompetentes. Para Carvalho (2008), a estratégia de utilizar toalhas, capas, cortinas e afins para esconder objetos mecânicos, associados ao trabalho doméstico, ou considerados "feios", fazia parte de uma rotina voltada à construção do conforto visual em interiores domésticos burgueses novecentistas.

A associação dos cômodos para casal com características convencionadas como femininas é tensionada, no contexto da mostra, em ambientes como o "Home privativo do casal", exposto em 2016 pela arquiteta Mariana Paula Souza. Nele, é possível observar a predominância de

\footnotetext{
6 Imagem disponível em Nessi (2013).

${ }^{7}$ Para uma discussão mais aprofundada sobre o tema, ver Zacar e Santos (2019).

8 Imagem disponível em: <https://casacor.abril.com.br/wp-content/uploads/sites/7/2016/11/20-homeprivativo-do-casal-mariana-paula-souza-casacor-sc-2016.jpeg?quality=80\&strip=info\&w=919>. Acesso em: 15 dez. 2020.
} 
características historicamente identificadas como masculinas ${ }^{9}$, tais como o uso de linhas retas e de materiais como a madeira e o couro, neste caso utilizados como revestimento para as paredes. A aplicação desses materiais também se relaciona com o uso dado ao ambiente, uma vez que podem auxiliar no seu isolamento acústico.

Destacam-se no cômodo duas chaises, móveis alongados para sentar que sugerem posturas mais informais e relaxadas. A forma como foram dispostas prevê uma certa distância entre os corpos, o que pode tanto ser entendido como um menor grau de intimidade entre cônjuges quanto como um indicativo de um maior nível de autonomia e independência de ambos.

A imagem de divulgação do ambiente dá centralidade ao equipamento de home theater, composto por projetor, telão e caixas de som. A valorização desse tipo de tecnologia, associado ao conforto e à praticidade, e também ao respeito à manutenção da individualidade, é recorrente nos discursos associados à mostra (ZACAR, 2018).

\section{Ambientes de uso compartilhado projetados para irmãos e irmãs}

Nota-se que na CCPR a individualização dos espaços é um aspecto presente tanto na definição de cômodos - identificados de acordo com a função e o perfil de usuárias/os imaginadas/os quanto no arranjo interno de ambientes, especialmente no caso de dormitórios idealizados para uso compartilhado. O "Quarto dos gêmeos"10, projetado por Margit Soares para "irmãozinhos de 2 anos - menino e menina" (CASA CLAUDIA, 2002), é um exemplo explícito da demarcação de áreas individuais no interior de um cômodo.

Nesse dormitório, exposto em 2002, as áreas destinadas a cada criança apresentam configuração similar. Cada uma possui uma cama com encosto estofado, coberta com três almofadas, e um baú também estofado, localizado no pé da cama. Essas áreas são, porém, diferenciadas pelo uso do rosa e do azul nos estofados, padrão cromático que reforça a oposição binária feminino/ masculino.

A convenção de uso da cor rosa para meninas e da cor azul para meninos, atualmente bastante difundida, foi estabelecida na primeira metade do século XX (KIRKHAM; ATTFIELD, 1996, p. 5). Para Jane Gallop (1986 apud HENDERSHOT, 1996, p. 101), nestas relações, o rosa fica marcado não só como feminino, mas como a cor da própria diferença de gênero. Isso porque o azul, fora do domínio de produtos infantis, não é considerado uma cor particularmente masculina, sendo que o rosa permanece, em geral, caracterizado como feminino.

No caso em análise, chama a atenção a necessidade de marcar de forma muito óbvia a área destinada a cada uma das crianças, idealizadas como sendo tão jovens. Como argumenta a historiadora Cheryl Buckley (1986), o consumo de produtos para bebês é parte de um processo de atribuir identidade à criança, que se inicia antes do seu nascimento. Aparentemente, em um momento em que a identidade de gênero ainda está em gênese, há uma ânsia por identificá-la,

\footnotetext{
${ }^{9}$ Essas características poderiam sugerir que o espaço foi projetado para um casal de usuários imaginados como gays, fato não explicitado no texto de divulgação do ambiente.

${ }^{10}$ Imagem disponível em Casa Claudia (2002).
} 
diferenciá-la e fixá-la, reforçada por meio do design de produtos infantis e da publicidade. Tratase, portanto, de uma produção prostética do gênero no qual, desde muito cedo, os artefatos que cercam as crianças contribuem para a constituição de certos comportamentos, formas de interação social, posturas e gestos que reforçam as normas de gênero.

Curiosamente, no caso do ambiente analisado, a necessidade de diferenciação é apresentada como demanda das próprias crianças, que "convivem no mesmo quarto sem abrir mão de uma decoração personalizada" (CASA CLAUDIA, 2002).

Em uma das paredes se veem as letras "A", "B" e "C" aplicadas em branco sobre um padrão xadrez nas cores rosa e azul. Sua presença remete ao processo de alfabetização e evidencia a preocupação com a educação que, para o historiador Philippe Ariès (2014), é uma característica fundamental para compreender a constituição das noções de infância e de família nuclear moderna. Segundo o autor, notadamente a partir do século XVII, formou-se uma concepção moral da infância que associava sua aparente fraqueza à sua inocência. A família deveria se organizar, portanto, para garantir a educação das crianças, tida como algo central para seu adequado desenvolvimento.

Outro exemplo de individualização de áreas dentro de um mesmo ambiente infantil é o "Quarto das crianças"11, apresentado por Cristiana Brenner e Luiz Mori Neto em 1997. Nele, a diferenciação é mais sutil do que no caso anterior. Os nomes das crianças imaginadas, Cris e Luiz, foram gravados em relevo no barrado de gesso, para designar o espaço destinado a cada uma, mas o padrão de cores e materiais utilizado é similar para ambas.

Tons de azul, verde, laranja, lilás e amarelo, foram escolhidos para conferir uma ideia de "neutralidade" associada à infância. Os elementos de diferenciação utilizados foram, principalmente, a configuração das colchas e os brinquedos. A colcha da cama da menina é mais comprida, e apresenta um detalhe de abotoamento nas extremidades. A do menino parece ser mais simples e fácil de arrumar.

Para ambas as crianças, a maior parte dos brinquedos disponíveis é de bichos de pelúcia, artefatos que podem ser associados a scripts específicos. Este tipo de brinquedo é comumente direcionado às meninas, por proporcionar brincadeiras em geral mais passivas e voltadas aos ambientes internos (FUNCK, 2004; CALDAS-COULTHARD; VAN LEEUWEN, 2004). Há, porém, diferenças entre os bichos associados à menina e ao menino. Aqueles próximos à cama da menina se apresentam usando vestidos floridos e rodados, que podem ensejar a brincadeira de vesti-los e desvesti-los - aproximando-os de bonecas. Já os brinquedos destinados ao menino são predadores - um tigre e um urso. $\mathrm{O}$ tigre branco sobre a cama remete aos troféus de caça (prática tida como masculina), cujas peles podem ser usadas no chão ou nas paredes como elementos decorativos.

No chão, próximo à cama do menino idealizado, encontra-se uma bola de basquete, e sobre a cama da usuária imaginada, um livro. Esses elementos reforçam estereótipos, vinculando a menina a uma atividade mais calma e reflexiva, e o menino a um esporte, que remete à ação e à competitividade (FUNCK, 2004; KIRKHAM; ATTFIELD, 1996). Por outro lado, a presença do

${ }^{11}$ Imagem disponível em Casa Claudia (1997). 
livro associa a figura feminina à uma atividade intelectual, aproximando-a do ideal de racionalidade comumente considerado masculino.

Como contraponto aos ambientes projetados para serem usados conjuntamente por um menino e uma menina, notamos que em exemplos em que o dormitório é dividido por duas meninas, como no caso do "Quarto das gêmeas"12, projetado pelas arquitetas Mariana Stockler e Carolina Posanske para a mostra de 2018, a necessidade de demarcação de áreas para cada uma se mostra atenuada.

Apesar de o texto de apresentação destacar a intenção de "criar um ambiente que estimulasse o vínculo entre as irmãs, porém, mantendo a individualidade de cada uma" (CASACOR, 2018), as áreas de descanso são configuradas por meio de espelhamento vertical, com pouquíssimas diferenças. Dentre elas, uma leve variação na cor das colchas e da pintura aplicada às molduras que dão acesso às camas. Em uma das paredes nota-se a duplicação de objetos decorativos idênticos - dois quadros e dois bonecos de pelúcia - o que também demonstra que, nesse caso, a necessidade de individualização e diferenciação parece amenizada.

No texto de apresentação desse espaço, os móveis de linhas retas são associados a um estilo "clean e contemporâneo", que contrasta com representações de flores que pendem de estruturas presas ao teto. Esses elementos visam conferir "delicadeza", tornar o espaço "feminino, lúdico e encantador para as pequenas usuárias" e ainda sugerir a "integração com a natureza desde a primeira infância" (CASACOR, 2018). Dessa forma, persiste a associação de um ideal de feminilidade com atributos como a delicadeza, materializados em elementos decorativos que remetem à natureza.

\section{Considerações finais}

A partir de nossas análises, sugerimos como projetos de design de interiores podem construir ideias e difundir valores sobre o matrimônio. No contexto da mostra, esse tipo de união, presumido como monogâmico e heterossexual, é representado como sólido e duradouro, baseado na complementariedade entre cônjuges e, ao mesmo tempo, na manutenção das individualidades. Observamos ainda como, em alguns casos, percebe-se a preferência pelo uso de elementos tidos como femininos na decoração dos dormitórios para casal, reforçando a ideia de uma apropriação inespecífica e extensiva da figura feminina em relação aos interiores domésticos, aspecto que remonta aos interiores novecentistas.

A preocupação com a manutenção das individualidades é observável também em relação a dormitórios infantis. Dentre os casos apresentados ao longo do texto, indicamos que, quando idealizados para o uso compartilhado por um menino e uma menina, tendem a apresentar demarcações das áreas destinadas a cada um/a, seja por meio da aplicação das tradicionais cores azul e rosa, seja pela inserção de brinquedos que sugerem diferentes scripts e carregam

12 Imagem disponível em: <https://casacor.abril.com.br/wp-content/uploads/sites/7/2018/06/quarto-degecc82meas_mariana-stockler-e-carolina-posanske_fotos-marcelo-stammer-

10.jpg? quality=80\&strip=info\&w=918>. Acesso em 15 dez. 2020. 
significados distintos. Dessa forma, fica explicitado que além do caráter individualizador, esses recursos têm função de marcação de gênero.

Ressaltamos que as estratégias de demarcação de áreas femininas e masculinas em um mesmo cômodo, em geral, se limitam aos dormitórios infantis e para casais. Isso porque no caso dos ambientes para adolescentes, jovens e adultas/os, o mais comum é que sejam configurados como cômodos ou moradas compactas idealizados para uso individual. Esse aspecto evidencia uma especificidade de classe, já que para grande parte das/os brasileiras/os, de diferentes faixas etárias, os ambientes domésticos precisam ser compartilhados devido às limitações impostas pelo espaço físico de suas moradias.

Notamos que ambientes expostos na mostra (re)produzem padrões de configuração que remetem aos interiores novecentistas, o que revela o caráter conservador das normas de gênero no contexto analisado. Ao mesmo tempo, apesar de serem perceptíveis continuidades com relação às características historicamente associadas à decoração tida como feminina ou como masculina, notam-se também, no recorte temporal analisado, algumas atualizações, deslocamentos e tensionamentos, o que nos permite destacar o caráter contingente das normas de gênero.

Ao entender o design de interiores como prótese de gênero, procuramos reforçar que os espaços e artefatos projetados definem noções de feminilidades e masculinidades mediante a sugestão de práticas e interesses específicos e a construção de visualidades que direcionam a certos significados. Nesse sentido, assumimos que nos projetos de design de interiores são inscritos scripts de gênero, a partir das ideias que as/os projetistas constroem sobre mulheres e homens, meninas e meninos. Assim, procuramos argumentar como as materialidades resultantes da prática do design de interiores participam da construção de posições de sujeito que somos convidadas/os a ocupar quando delas nos apropriamos. Dessa forma, ressaltamos que o design não é neutro, mas uma produção cultural comprometida com a construção, circulação e consumo de significados socialmente compartilhados, de hierarquias de valores e de perspectivas sobre as identidades e as diferenças.

\section{Referências}

ARIÈS, Philippe. História social da criança e da família. 2 ed. Rio de Janeiro: LTC, 2014.

BUCKLEY, Cheryl. Made in Patriarchy: Toward a Feminist Analysis of Women and Design. Design Issues, Cleveland, v. 3, n. 2, p. 3-14, 1986.

BUTLER, Judith. Regulações de gênero. Cadernos Pagu, Campinas, n. 42, p. 249-274, jun. 2014.

CALDAS-COULTHARD, Carmen Rosa; VAN LEEUWEN, Theo. Discurso critico e gênero no mundo infantil: brinquedos e a representação de atores sociais. Linguagem em (Dis)curso - LemD, Tubarão, v. 4, n.esp, p. 11-33, 2004.

CARVALHO, Vânia Carneiro de. Gênero e artefato: o sistema doméstico na perspectiva da cultura material: São Paulo, 1870-1920. São Paulo: EdUSP, 2008.

CASA CLAUDIA. Casa Claudia apresenta CASACOR Paraná 2002. Casa Claudia, São Paulo, ano 26, n.05, 2002. 
CASA CLAUDIA. Casa Claudia apresenta CASACOR Sul - Paraná' 97. Casa Claudia, São Paulo, ano 21, n. 6, 1997.

CASACOR. Press Kit CASACOR Paraná. 2018. Disponível em: <https:// casacor.abril.com.br/contatos-imprensa/>. Acesso em 10 jun. 2020.

CASACOR. Press Kit CASACOR Paraná. 2019. Disponível em: <https:// casacor.abril.com.br/contatos-imprensa/>. Acesso em 10 jun. 2020.

FUNCK, Susana Bornéo. Anjos e feras no espaço doméstico: decoração para meninas e meninos. In: COSTA, Cláudia de Lima, SCHMIDT, Simone Pereira (orgs.). Poéticas e políticas feministas. Florianópolis: Ed. Mulheres, 2004.

GRUPO ABRIL. Mídia Kit CASACOR 2017. São Paulo, 2017. Disponível em: <http:// publiabril.abril.com.br/ marcas/casacor>. Acesso em: 16 maio 2017.

GERVEREAU, Laurent. Ver, compreender, analisar as imagens. Lisboa: Edições 70, 2004.

GURGEL, Miriam. Projetando espaços: guia de arquitetura de interiores para áreas residenciais. São Paulo: Senac São Paulo, 2013.

HENDERSHOT, Heather. Dolls: odour, disgust, femininity and toy design. In: KIRKHAM, Pat (Ed.). The gendered object. New York: Manchester University Press, 1996.

KIRKHAM, Pat; ATTFIELD, Judy. Introduction. In: KIRKHAM, Pat (Ed.). The gendered object. New York: Manchester University Press, 1996.

MANCUSO, Clarice. Arquitetura de interiores e decoração: A arte de viver bem. Porto Alegre: Sulina, 2002.

MANDELBAUM, Belinda. Novas Famílias? Uma indagação sobre as novas configurações familiares. Sesc São Paulo, São Paulo, 03 nov. 2009. Disponível em: <http:// www.sescsp.org.br/online/artigo/5340_EM+ PAUTA\#/tagcloud=lista>. Acesso em: 25 fev. 2016.

MAUAD, Ana Maria. Na mira do olhar: um exercício de análise da fotografia nas revistas ilustradas cariocas, na primeira metade do século XX. Anais do Museu Paulista, São Paulo, v.13, n.1, p. 133-174, jan. - jun. 2005.

MOTA, Lara. Falta menos de um mês para a CASACOR Paraná 2012. Gazeta do Povo, 03 maio 2012. Disponível em: <http://www.gazetadopovo.com.br/haus/eventos/falta-menos-deum-mes-para-a-casa-cor-parana-2012/>. Acesso em: 12 jul. 2014.

NESSI, Marina. Estilo Curitiba: os 20 anos da CASACOR Paraná. Curitiba: Edição da autora, 2013.

PRECIADO, Beatriz. Manifesto contrassexual: práticas subversivas de identidade sexual. São Paulo: n-1, 2014.

PRECIADO, Beatriz. Pornotopía: arquitectura y sexualidad em "Playboy" durante la guerra fría. Barcelona: Editorial Anagrama, 2010.

PUGLIESI, Maria Helena Pugliesi. Em rota de expansão. In: CASACOR PARANÁ. Revista CASACOR Paraná 2014. Curitiba: PR Premium Promoções e Comercial LTDA, 2014, p. 42.

ROSE, Gillian. Visual Methodologies: an introduction to the interpretation of visual materials. London: Sage Publications, 2007.

ROSSETTI, Eduardo Pierrotti. Morar brasileiro: Impressões e nexos atuais da casa e do espaço doméstico. Arquitextos, São Paulo, ano 15, n. 169.01, Vitruvius, jun. 2014. Disponível em: $<\mathrm{http} / / / \mathrm{www} . v i t r u v i u s . c o m . b r / r e v i s t a s / r e a d / a r q u i t e x t o s / 15.169 / 5220>$. Acesso em: 12 jan. 2016. 
SANT’ANNA, Denise Bernuzzi. História da beleza no Brasil. São Paulo: Contexto, 2014. [versão Kindle]

SANTOS, Marinês Ribeiro dos. O Design Pop no Brasil dos anos 1970: Domesticidades e relações de gênero na decoração de interiores. Curitiba: Ed. UFPR, 2015.

SPARKE, Penny. An introduction to design and culture: 1900 to the present. 2nd edition. London: Routledge, 2004.

VAN OOST, Ellen. Materialized Gender: How shavers configure the user's femininity and masculinity. In: OUDSHOORN, Nelly; PINCH, Trevor (Eds.). How Users Matter: The CoConstruction of Users and Technology. Cambridge/London: MIT Press, 2003. p. 193-208.

ZACAR, Cláudia Regina Hasegawa. O design de interiores como prótese de gênero: um estudo sobre a Casa Cor Paraná (1994-2017). 2018. 268 f. Tese (Doutorado em Tecnologia e Sociedade) - Programa de Pós-graduação em Tecnologia e Sociedade, Universidade Tecnológica Federal do Paraná, Curitiba, 2018.

ZACAR, Cláudia Regina Hasegawa; SANTOS, Marinês Ribeiro dos. Relações de gênero no design de interiores: o uso de referências à natureza na configuração de ambientes femininos e masculinos expostos na Casa Cor Paraná. PROA Revista de Antropologia e Arte, v. 2, n. 9, 2019. Disponível em: <https://www.ifch.unicamp.br/ojs/index.php/proa/article/ view/3289>. Acesso em: 26 jun. 2020.

ZACAR, Cláudia Regina Hasegawa; SANTOS, Marinês Ribeiro dos. A materialização de masculinidades gays no design de interiores: um estudo sobre a mostra Casa Cor. 13th Women's world \& Fazendo Gênero 11, 2017, Florianópolis. Anais eletrônicos... Florianópolis: UFSC, 2017. Disponível em: < http://www.wwc2017.eventos.dype.com.br/ resources/anais/1498669329_ARQUIVO_Fazendogenero_ZacareSantos_Final_ajustado.pdf >. Acesso em: 15 dez. 2020.

WEEDON, Chris. Subjectivity and identity. In: WEEDON, Chris. Identity and Culture: Narratives of Difference and Belonging. Berkshire: Open University Press, 2004. p. 5-21.

\section{Sobre as autoras}

Cláudia Regina Hasegawa Zacar é doutora em Tecnologia e Sociedade pela Universidade Tecnológica Federal do Paraná e docente no curso de Design de Produto do Departamento de Design da Universidade Federal do Paraná. Seus interesses de pesquisa incluem: teoria e história do design, estudos da cultura material, estudos de gênero, design de interiores e design de produto. https://orcid.org/0000-0002-1756-2347

Marinês Ribeiro dos Santos é doutora em Ciências Humanas pela Universidade Federal de Santa Catarina (2010) e docente do Departamento Acadêmico de Desenho Industrial e do Programa de Pós-Graduação em Tecnologia e Sociedade na Universidade Tecnológica Federal do Paraná. Seus interesses de pesquisa estão focados nos Estudos em Design, com ênfase na cultura material e suas interfaces com o espaço doméstico e com as relações de gênero.

https://orcid.org/0000-0002-9925-9949 